\title{
The Teaching of Civic Education in Selected Secondary Schools in Lusaka Province of Zambian: A Tool for Conflict Resolution in the Community
}

\author{
Davy Mainde and Gistered Muleya \\ The University of Zambia
}

\begin{abstract}
This study investigated the teaching of Civic Education and how it serves as a tool for conflict resolution in the community. Qualitative case study design was used and 12 participants (8-Civic Education teachers and 4-deputy headteachers) from four selected secondary schools in Lusaka Province of Zambia were purposively selected through homogenous sampling. One-on-one interviews were used to collect data from both teachers of Civic Education and deputy head-teachers. Thematic data analysis was used in this study. The study established that Civic Education provides awareness to citizens on fundamental rights and freedoms; empower citizens for effective participation in decision making, produce critical thinkers, impart learners with conflict resolution skills, used as a strategy for curbing social challenges and helps in the appreciation of cultural diversity in communities. Civic knowledge, skills and values embedded in Civic Education have a potential to transform a violent to a peaceful community. The study recommends that Continuous Professional Development (CPD) activities such as Lesson Study Circle, Cluster Meetings and Professional Subject Associations Workshops must be strengthen in schools to revive Civic Education teachers with new knowledge and skills in teaching Civic Education for conflict resolution in communities. Further, the government should come up with a clear policy that will empower young people through the teaching of Civic Education to organise school associations aimed at promoting peaceful core-existence in multicultural communities as outline in the 2013 Zambia education curriculum framework. This study act as an eye opener to policy makers and implementers to use nonviolent approaches such as teaching of Civic Education in secondary schools in denouncing conflict in communities.
\end{abstract}

Key Terms: Civic Education, Conflict, Conflict Resolution.

\section{INTRODUCTION}

$\mathrm{C}$ onflict is inevitable and occurs from place to place and individual to others due to variety of human interests and community's dynamics. From the antiquity to contemporary times, competitions and conflict are regarded as inherent phenomena in both nature and society (Jung, 2003). Once there is cause for inter-group relations, conflict becomes inevitable and peace must be given a chance (Olaniyi, 2009). Conflict can be caused by many factors which include; fraud in the electoral system, failure of governance systems, economic resources, religious beliefs, artificial boundaries, land ownership, global repression, ethnicity and identity (Nebe, 2012; \& Ebimaro, 2008). Conflict emanate from individual inert and grows until it reaches a latent or violent stage. Latent or violent social confrontations have long been considered as the premium mobile for social changes and transformations (Rugumamu, 2002).

At any stage, society have tried to use several conflict resolution strategies to avoid violent conflict which may lead to destruction of properties, loss of lives, or any other social disorder such as internal and external displacements. Haider (2014) explained conflict resolution strategies as, timely and appropriate prevention initiatives, usually undertaken during dormant stages of perceived potential violent conflict. These strategies includes; avoidance, compromise, flight, forcing, collaboration, flow pattern, accommodating, threats, and fighting (Ebimaro, 2008). Conflict resolution is not only important, the method employed in the settlement matters more in the sense that it satisfies the parties to the conflict. However, these have limitations and can only be used when there is a sign of conflict in the community.

In addition to the foregoing conflict resolution strategies, this study proposes the teaching of Civic Education in secondary schools as one of the tools for settling conflict in communities. This is because there is a profound relationship between education and conflict, hence education has a critical role in peace-building. According to Kotite (2012), Civic Education by its very nature contributes to shaping and transforming society and therefore plays a critical role in peace-building. Civic Education enlightens citizens with their fundamental rights and freedoms (civic knowledge), empowering them for effective participation (civic skills) and instil them with good virtues (civic disposition) which society needs in order to live in harmony.

\section{Problem Statement}

Though conflict is inevitable in the community, the existence of strategies to mitigate it renders it manageable. Different political governments in Zambia have tried to quench it through the use of law enforcing institutions such as police service and court systems. Because of political attachment, these institutions in most times finds it difficult to provide equal justice. One of the approach which can be trusted to reduce conflict is the provision of Civic Education to the public. Civic Education encompasses harmonious branches which are; civic knowledge, civic skills and civic dispositions 
to conflict resolution (Branson \& Quigely, 1998; Piñgul, 2015; Debbie \& Stacey, 2016). Further, Citizenship or Civic Education sharpens critical thinking capacities of young people which is important in the analysis of political, social, and other issues as well as preparing them for their roles and responsibilities and challenges an uncertainties of life through provision of relevant education (Muleya, 2019). According to Vasiljevic (2009), and Makano and Mukanda (2019), Civic Education provide avenues for human rights protection, developing conflict resolution skills and non-violent communications in communities.

Since its reintroduction in 2003 under pilot project in three provinces of Zambia (Lusaka, Central and Northern Province), Civic Education has helped in empowering citizens with democratic dispensations in Zambia as well as promoting justice in the community (Katongo, 2013). The subject is concerned with imparting civic knowledge, civic skills and civic dispositions to learners in secondary schools (McCowan, 2009). On the other hand, Halstead and Pike (2006) identified essential values of a civilised society as; human rights, tolerance, respect for persons or anti-racism which if learnt in Civic Education have potential to promote peaceful way of resolving conflict in communities. Thus, the teaching of Civic Education is expected to promote a peaceful conflict transition and discourages coercion process to settle disputes.

With all these Civic Education treasures, Zambia has exhibited numerous conflicts both structural and direct at various levels. Lives have been lost, properties destroyed; citizens have lost brotherly love in preference to party affiliation, a lot of injustice in the application of the law to favour party in government' stalwarts, suppression of the vulnerable by guardians of instrument of power, lack of selfintrospection by those in public office and many others. In all these incidents, youths involvement especially where violence is concerned has never been silent. However, these youths were the targets for the reintroduction of the teaching of Civic Education in secondary schools so that they can understand and live up to democratic tenants. This leaves a room to wonder whether the teaching of Civic Education in Zambian secondary schools has addressed important issues such as denouncing of conflict in preference for peaceful coexistence. For this reason, this study sought to investigate the teaching of Civic Education and how through its elements (civic knowledge, civic skills and civic dispositions) serves as a tool for conflict resolution in the community.

\section{Purpose of The study}

From the above, it is clear that conflict of different nature has con manifesting itself in the Zambian community despite a lot of eff curb the vice. The main purpose of this study was to examin teaching of Civic Education in selected secondary schools in L province of Zambia and how it serves as a tool for conflict resolu the community.

\section{Conceptual Framework}

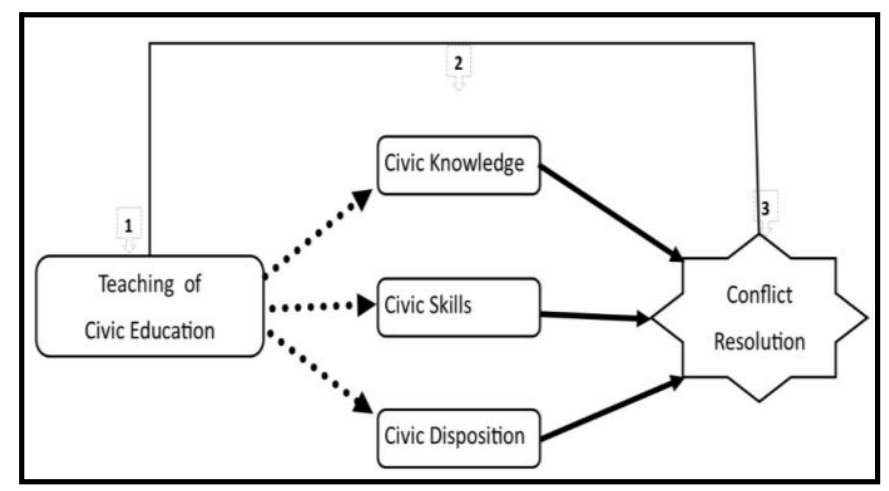

The above model is the conceptual framework which guided this study. It is made up of the three strands of Civic Education which are civic knowledge, civic skills and civic dispositions or values. These are to be acquired by a learner who has done Civic Education and should help him or her take a leading role in conflict resolution process in the community. Through this knowledge, people are aware of the civic responsibilities and duties towards each other in the community. The teaching of Civic Education provide skills needed for critical thinking, analyses of issues and formulation of opinions. Civic Education also helps learners to change their mind-set from involvement in conflict to cherishing peace. Therefore, this conceptual framework, based on learners' acquisition of civic knowledge, civic skills and civic dispositions or values is assumed to integrate the interaction between teaching Civic Education in Zambian secondary schools and conflict resolution in communities.

\section{RELATED LITERATURE TO THE STUDY}

\section{The Concept of Conflict}

Conflict is a complex phrase which can be defined differently according to scholars' field of orientation. Ebimaro (2008) defines conflict as the pursuit of incompatibility of goals by individuals or groups as a result of the inability of social structure to allocate values objectively. It is a disagreement that generates from distributive injustice. Conflict may be defined as a struggle or contest between people with opposing needs, ideas, beliefs, values, or goals (Thakore, 2013). Since people's culture is dynamic, conflict is caused when there is clash in cultural practice among the people living in the same geographical settings. Cosrer in Otite and Albert (1999) calls this kind of conflict as 'social conflict'. Social conflict is said to be a struggle over values or claims to status power, and scarce resources, in which the aims of the conflicting parties are not only to gain the desired values, but also to neutralize, orts to or eliminate their rivals. It is a great creative and everpresent force that leads to social change. This kind of conflict cusaka gers economic development and overall standard of iiving. Thus why Olaniyi (2000) observed that, conflict exists when two people wish to carry out acts that are mutually inconsistent. They will want to do the same thing or do different things that are incompatible. In the pursuit of 
upholding one's culture, one may cause conflict as his or her practices may not be consistent with other members of the same heterogeneity society. According to ACCORD (2011), conflict may be viewed as a form of tension arising from mutually exclusive or opposing actions, thoughts, opinions, or feelings. In the study by Robbins (2005), conflict is seen as a process that begins where one party perceives that another party has negatively affected or is about to negatively affect something that the first party cares about.

There are two forms of conflict which are structural or indirect violence and direct conflict. Structural or indirect violence is a form of violence which are reproduced along a range of collective beliefs, values and norms that impact how people relate to each other and within societal and institutional structures leading to inequality, discrimination and injustices (Reyes, 2015; \& Galtung, 1969). According to Stiles (2011), the poor remains in poverty not because they want to, but because of many barriers deliberately built around them by those who benefit from their poverty. There may be no physical harm caused, but such treatments makes the affected individuals uncomfortable. According to Clark (1989) they are underlying conditions, structures and systems that have existed for many years, and are mostly static or change slowly over time, and so form the basis for long-term risk assessment. UNDP (2017) established that, structural factors in Zambia tend to be embedded in cultural and institutional contexts such as unequal integration in the multi-ethnic or sectarian conflicts, political and economic marginalization, long-standing electoral disputes, and poverty among others. These are havens of structural violence in communities. On the other hand, direct conflicts or physical violence are those that hurt human beings somatically, to the point of killing people, psychologically harmed, mal-developed or deprived through violent socioeconomic or political structures (Galtung, 1969; \& Salvage, et al., 2012). During war, the beatings, killing, and abuse are examples of direct conflict. At all levels, direct conflict is characterised by causing harm or pain on the recipient. Such acts to cause harm to an individual or groups of people is associated with basic interest by one party.

There are a number of causes of conflict in the community. These include; fraud in the electoral system, failure of governance systems, economic resources, religious beliefs, artificial boundaries, land ownership, global repression, ethnicity and identity (Nebe, 2012; \&Ebimaro, 2008). Agbu (2006) argued that, increasing loss of state capacities is a major cause of conflict in Africa. This is exacerbated due to unfulfilled promises arising from electoral campaigns which includes; enjoyment of freedom of expression, improving economic status and way of life of citizens (Kaumba, 2015). Such promises are easily said, but lack of implementation resulting to poor leadership skills by those who assume office.

\section{Stages of Conflict Development}

There are a number of stages involved in conflict development. The first is latent stage of conflict development. At this stage, participants are not yet aware of the conflict but hidden frustrations may surface at any time. Gultung (1969) added that latent violence is something which is not there, yet might easily come about. This is the first level in which people typically become aware that there is a problem. According to Ohana (2012), little is said or done about the problem at this stage as it is not recognised that any problem actually exists. If a solution is not found, especially because one of the parties sticks stubbornly to his or her point of view, the conflict escalates. Intensification or perceived or incidents is the second stage in conflict development where members are aware that a conflict exists (Ohana, 2012). It is characterised with the occurrence of minor but negative events which make the parties to be discontent and develop the feeling of tension to mistrust. Gultung (2000) noted that the parties may feel irritated with each other, fluctuations between co-operation and competition escalates.

When parties fail to resolve conflict at intensification stage, conflict may reach an escalation stage where members feel stressed, anxiety, and possibly hostility may occur depending on the situation (Ohana, 2012). It is likely that misunderstandings between two parties with opposing views have contributed to the problem. There is much of blaming the opponent for the cause of the problem. Confrontation is another stage in conflict development. According to Gultung (2000), confrontation level also known as the tension level follows very quickly as the situation deteriorates, and as a result parties view each other with deep suspicion. Typically there is a stiffness to their dealings with each other. Ohana (2012) noted that at this stage all behaviours in the relevant parties are viewed through the filter of mistrust and there is little or no trust in the relationships. At this level, both parties fear that the grounds for a common solution are lost. In other words, they lose hope for a reasonable outcome to resolve their dispute as interaction becomes hostile. The final stage in conflict development is crisis or manifest stage where the situation develops into a crisis level as the parties reach a phase of outright hostility and it is clear by this time that events have reached a serious stage indeed. When this level is reached, it is unlikely the parties will be able to resolve the conflict without external and professional assistance or intervention.

\section{Conflict Resolution Strategies}

There are a number of strategies which can be employed to curb conflict in the community. To start with, conflict can be resolved through avoidance. Avoidance response also known as flight approach is a situation where a group alleging injustice or discrimination is literally ignored or denied recognition by those being accused and those who have the capacity for helping to redress the injustices done to the group (Victor, 2012). Flight behaviour in conflict management may 
firstly and partially involve withdrawing to avoid the conflict and just keeping the peace. The intention which may be unconscious is to protect oneself rather than dealing with the problem. It involves denial of the conflict, equivalent switching and avoiding issues, being non-committal, joking instead of dealing with the conflict and paying undue attention to irrelevant and inconsequential issues (Gonclaves, 2008). This might worsen issues and propels the party ignored or avoided to violent or extra-judicial actions. Additionally, the approach does not address underlying issues to the conflict, hence, there is high chances of conflict resurfacing in future. According to Nelson and Quick (1997), the flight approach to conflict management permits conflicts to deteriorate rather than giving room for improvement. It reinforces the negative notion about conflict as always destructive and must be avoided. The other demerit of using the flight approach is that it blocks the chances of exploring the potentials for development inherent in the issues in conflict. There is restriction of each party to their own group and narrow perceptions about the issues in contentions. This tactic often prepares the theatre for violent conflict or war in future.

Compromise is another strategy in which disputing parties responds to their differences. Ryan (2015) explained that disputants reach a solution acceptable to all, so all sides are prepared to lose something as well as win something. Victor (2012) argues that compromise approach can be identified as bargaining or trading to conflict. It involves the parties laying bare cards and making concessions which ordinarily might not have appealed to them. Thakore (2013) postulated that compromise is often adopted in extreme situations where the parties cannot move forward without making concessions on some of their demands. The method sounds better as both parties are willing to gain or lose something as a way of resolving their differences. The parties in conflict negotiate and bargain as a way to reach a conclusive solution to the problem. This is also useful in conflicts characterised by limited resources where parties may need to be contented with available resources even when it is not in conformity with their desires. Nevertheless, if this approach is used excessively or exclusively, it may lead to simply making everybody happy, without resolving underpinning factors for the original of conflict. As a result, it does not contribute to building trust in the long term.

Flow pattern is yet another response to conflict which seek to satisfy the needs of both parties without hurting anyone. The approach is usually applied by considerate parties who respect other people's feelings, ideas and conscience. It is termed as the best approach as it involves a win-win situation. The flow pattern approach which is also called a collaborating approach, includes listening to needs and goals of another party towards achieving a common goal (Victor, 2012). It means reaching a better solution through communication and co-operation by parties involved. This style seeks to solve the issue whilst respecting every stakeholder to the conflict. Hence, this increases trust and respect and eventually leads to effective collaboration in the future. Individuals using this type of conflict style tends to be highly assertive and highly empathetic (Bayazit, et al., 2003) as it gives them chance to share risks and responsibility of the outcome. This style is adopted when maintaining harmony is important. Victor (2012) noted that individuals smooth over the conflict out of fear of harming the relationship, their unassertive and cooperative behaviour creates a win-lose situation that is accepted and liked by others. Parties to the conflict think that conflict should be avoided in favour of harmony and that people cannot discuss conflicts without damaging relationships.

However, the flow pattern approach to conflict management requires a contribution of all parties to find a mutually acceptable solution. Because of that, it can take a lot of time and efforts than other strategies. It cannot be practical approach because the time is an important factor in conflict resolution. If the trust is lost, relationships can be spoiled hence individuals or groups will be made to choose other methods of settling conflict. According Thakore (2013), one party adopting accommodating conflict management style will show little concern to own personal interests, instead focus on maintaining relationship with the other. Individuals ignore their own goals and resolve conflict by giving in to others because they see the relationships as of the greatest importance while their own goals are of the least importance.

Another strategy for conflict resolution is threats or confront response. According to Ryan (2015), threats is among common strategies used in responding to conflict in communities through which one party submits by the way of withdrawing from the conflict. The party which thinks is strong will use threats or force to make the other realise that withdrawing from the conflict is ideal than searching for possible peaceful resolution which might be futile (Victor, 2012). Thakore (2013) explained this style as most practical to find an integrative solution when both sets of concerns are too important to be compromised and to work through feelings that have inferred with a relationship. The party which withdraws might not be satisfied on how the conflict have been resolved through this style, hence might seek for allies or mobilise resources in order to subdue the opponent through direct conflict. Therefore, this method is seen as temporal and unstable in resolving conflict.

Thakore (2013) and Victor (2012) identified fight strategy which is also known as competing approach as another style in which conflict can be resolved in the community. This method entails one party or group winning while the other party or group losing conflict. During fight behaviour, the intention which may be unconscious is to come down hard on the issue, with little concern for the person (Gonclaves, 2008). The approach is generally characterized by aggressive communication behaviour that is threatening and seeking control of the opponent or using of force to subdue the opponent. In this approach, one puts personal needs and feelings first and has determination to conquer. Participants do not accept the blame and punishment, as they all feel are right 
and the other is wrong until they engage in a fight. This approach may be appropriate when quick actions are needed, especially during emergencies. Also it can be useful when an unpopular solution must be applied and a deadline is near. However, this style is inappropriate in an open and participative climate (Victor, 2012). It creates enemies between parties involved and a grudge by the losing side. Bobbins (1974) observed that this conflict management style may negatively affect relationships with the opponent in the long term. The approach also takes a lot of energy and can be exhausting to some individuals or society as it requires a lot of resources to engage in this response to conflict.

From the foregoing discussion, it can be ascertained that these responses are appropriate before conflict turns into direct violence. They are employed when some signs to outbreak of conflict are seen in an individual or community. Therefore, they may not be sustainable to end conflict in communities. There is a need to develop a strategy which may pervasively encourage peaceful co-existence and denounce conflict in the community. This study investigated the teaching of Civic Education in selected secondary schools in Lusaka Province of Zambia and how it serves as a sustainable tool for conflict resolution in the community.

\section{The Concept of Civic Education}

There are contentious debates to have a universal definition of Civic Education also known as Citizenship Education. Citizenship Education is increasingly re-framed through different points that have emerged as key arenas in which the formal rights and duties of citizens are understood, expressed, and enacted on a daily basis (Muleya, 2015; 2018; 2019). Eurydice Report (2017) also justified the fluidity of Citizenship Education which is associated with the existence of more than one definition and model of citizenship. For instance, the way Civic Education was defined in $19^{\text {th }}$ Century might not be the way the $21^{\text {st }}$ Century will mirror it due to complex dynamic of understanding people's aspirations in socio-economic and political organisations in time space. Civic Education is education in self-government (Branson \& Quigley, 1998); an organisation under education for Democratic Citizenship (Smith, et al, 2002); a way of learning for effective participation in a democratic and development processes (Vasiljevic, 2009); as that education which promotes recipients' understanding of the political system, their own interests, and options to contribute to government or citizens' rights and obligations (Satu, 2007); while Kerry (2012) described it as a policy initiated by a government, a program run in a school, a lesson taught by a teacher or an activity experienced by a student. To cement Kerry's view, Watler (2014), and Şanlı and Mehmet (2015) further guided that Civic Education in schools includes formal coursework in one's government on the principles and rules of democracy, human rights and freedoms. Civic Education sharpens critical thinking capacities of young people by enabling them to analyse political, social, and other issues, as well as preparing them for their roles and responsibilities and for the challenges and uncertainties of life through provision of relevant education (Muleya, 2019).

\section{Goals of Civic Education}

The study by Halstead and Pike (2006) reviewed the primary aim of Civic Education as for producing informed citizens. The course is intended to produce citizens who becomes custodian of knowledge, skills and who become role models in communities. McCowan (2009) explained that traditional Civic Education class emphasis on knowledge focusing on Constitution, government and political institutions, as well as national history. According to Kamp (2011), Civic Education equips citizens with the required awareness, knowledge and skills to be conscious and active political participants in the democratic society.

The teaching of Civic Education is aimed at producing a citizen who is committed to the public values of society. Halstead and Pike (2006) identify some of essential values to a civilised society as; human rights, tolerance, respect for persons or anti-racism which students need to learn in school. McCowan (2009) re-echoed that students develop greater understanding of their existing beliefs, commitment to specific moral and political vision of their community. Further, Halstead and Pike (2006) noted the value of Civic Education as to encourage the students to develop a substantive commitment to civic virtues or dispositions which allow the public values to flourish. Petersen (2011) argued that, civic obligation broadly comprises of duties expected of a citizen within a particular political community to perform.

The teaching of Civic Education helps young people become active participants in building and strengthening their communities. It equips citizens with skills to participate and contribute to the development and maintenance of democratic governance and citizenship which eventually leads to the establishment of a stable democratic political system (Crick, 200; \& Kaumba, et. al., 2020). According to Vasiljevi (2009), Civic Education aim at acquisition of knowledge about a constitution and the basic democratic institutions and regulations. Muleya (2015) suggests that the teaching of Civic Education is tailored on service learning for enhancement of social change and transformation of a society. Civic Education imparts knowledge to learners in order to transform their behaviour towards the common good of the community. Community involvement and service learning are all product of civic minded person.

According to Kamp (2011), Civic Education offers a major contribution by aiming at producing an informed, active and responsible democratic citizenry. In Zambia, Civic Education was introduced for the purpose of bridging the gap that existed between junior secondary and when someone graduate from tertiary institution. The study conducted which focused on the teaching of Civic Education in Zambia and Norway indicated that, the gap had an impact on grade 12 school leavers who in most instances had graduated with little or no experience of Civic Education concerning their rights, roles 
and obligations (Katongo, 2010). As a result, there was vacuum after pupils wrote their grade nine and the time before they got to tertiary institutions. There was also a need to facilitate children's participation in decision making and develop their capacity in planning, organizing and coordinating. Therefore, this call was fulfilled in 2003 when the Ministry of Education re-introduced the teaching of Civic Education in secondary schools which was banned in the 1978 due to political reasons. Civic Education has also been presented as a course which impart civic knowledge, civic skills, and civic disposition or values to learners which are useful in democratic dispensation (Crick, 2000; Halstead \& Pike, 2006; McCowan, 2009; Vasiljevi, 2009; Petersen, 2011; and Biesta, 2011). However, it would appear little has been done on the teaching of Civic Education in secondary schools in Zambia especially on how it serves as a tool for conflict resolution in the community.

\section{RESEARCH METHODOLOGY}

This study used a qualitative research approach that usually emphasises on words rather than quantifications in the collection and analysis of data (Bryman, 2008). The study sought to examine the teaching of Civic Education and how it serves as a tool for conflict resolution in the community based on expression of individual teachers (Creswell, 2003). In order to investigate in depth the teaching of Civic Education, a case study research design was used (Creswell, 2003). The researcher wanted to bring about deeper insights and better understanding of the problems faced by participants (Komb \& Tromp, 2006) in teaching Civic Education in relation to conflict resolution in selected secondary schools in Lusaka Province of Zambia.

\section{Population and Sample}

This study targeted professional teachers of Civic Education in selected secondary schools in Lusaka Province of Zambia. Study population is defined by Kombo and Tromp (2006) as a group of individuals, objects or items from which the samples are taken for measurement. A sample is a subset or small proportion of the population which has been selected for analysis and observation (Kahn \& Best, 2006). In this study, 8 teachers of Civic Education and 4 deputy head-teachers from 4 selected secondary schools in Lusaka Province of Zambia were sampled through purposive homogenous sampling (due to similar characteristics/ information they possess) to investigate how the teaching of Civic Education serves as a tool for conflict resolution in the community. School deputy head-teachers were included in this study because their offices are in charge of discipline within school environment. Therefore, 12-participants were sampled in this study for the purpose of collecting data.

\section{Data Collection Techniques}

This study used both secondary and primary data. Secondary data are those sources of information which have already been collected and analysed by someone else (Ranjit, 2005) which includes; news bulletins, magazines, newspapers, documentaries, advertising, the Internet, books and many others (Walliman, 2011). This study used books, journals and internet sites with related information on teaching Civic Education in relation to conflict resolution in communities. On the other hand, primary data is information direct collected from the informants through interviews or questionnaire (Ranjit, 2005) through observation, experienced or recording of an event. This study used primary data provided by teachers of Civic Education and deputy head-teachers on how the teaching of Civic Education serves as a tool for conflict resolution in the community. Primary data was collected through one-on-one interviews using an interview guide which comprised of a series of open ended questions (Musingafi and Hlatywayo, 2013) on the teaching of Civic Education and how it serves as a tool for conflict resolution in the community.

\section{Data Analysis}

This study used a thematic data analysis where emerging themes from informants' views became topics or headings (Kombo and Tromp, 2006) and were written according to their similarities. From the responses gathered, the researcher developed broad themes that reflect the meanings of the topic under investigation (Kothari, 1985).

\section{Ethical Considerations}

Cohen et al. (2007) defined ethical considerations as a correct behaviours and procedures that are necessary and in line with the recommended legal and ethical conduct of the researcher. In this study, interviewees' names are not mentioned, instead category coding was used in place of their actual names. Teachers' names were coded as $\mathrm{CET}_{1}, \mathrm{CET}_{2}, \ldots$ while deputy head-teachers were coded as $\mathrm{DHT}_{1}, \mathrm{DHT}_{2}, \ldots$. An informed consent was sought from respondents before conducting the interview and the researcher guaranteed them with security of the information provided. After the objective of the research was stated, respondents agreed to be interviewed and willingly to share their experiences on the teaching of Civic Education and how it serves as a tool for conflict resolution in the community. The researcher's made recordings were used only for the purpose of validation through counter checking of written data to what the respondent said, hence not available for public use.

\section{PRESENTATION OF FINDINGS}

\section{Civic Education as a Tool for Conflict Resolution}

Civic Education has multiple benefits to individual learners and the community. This study established that: respect for human rights, effective participation in decision making, effective leadership, critical thinking, skills for conflict resolution, strategy to curb social challenges, appreciation of cultural diversity and elimination of poverty as such benefits that can be identified in learning Civic Education at secondary school level in Zambia. These elements has a potential to lessen conflict in communities. 


\section{Respecting of Human Rights}

The study established that Civic Education in the secondary schools helps enlightening citizens with fundamental human rights and freedoms. This came out strongly from both teachers and school administrators. For instance, $\mathrm{CET}_{1}$ and $\mathrm{CET}_{2}$ said,

"I see the teaching of Civic Education at secondary school level to be helpful in enlightening citizens of their own rights and those of others. It helps in the understanding and appreciation of civic and political rights.... As for me, I think this is good enough to reduce conflict which might result from violation of ones' rights and freedoms Sir"

When the deputy head-teachers were asked how the teaching of Civic Education in school curb conflict occurrence, they also referred to benefits Civic Education has in enlightening the community with fundamental rights and freedoms. Their views can be represented by $\mathrm{DHT}_{1}$ who explained that,

"Sir, if people are ignorant of their rights and those of others, conflict in the community will continue to be recorded. Therefore, Civic Education has tremendous benefits of making those who are aware of human rights to have moral control on the rights of their fellows as they enjoy their own right".

\section{Effective Participation in Decision Making}

Another role Civic Education play in society is enhancing effective participation in decision making in communities. Most of interviewed Civic Education teachers brought out this argument as can be seen from $\mathrm{CET}_{3}$ who said,

“... Civic Education empowers citizens to participate in political, economic and social organisation in communities".

Further, school administrators shared similar view to those of teachers of Civic Education in which Civic Education helps providing knowledge and skills in decision making in the country. According to $\mathrm{DHT}_{2}$,

It is true the subject is rich in political content, for example, most of the countries including Zambia have been experiencing political intolerance and violence. All this is caused by lack of civic knowledge where they would be able to understand that other people have their own rights as well as they have theirs. Therefore, I see Civic Education if taken seriously, can help produce graduates with self-conscious for effective participation in decision making process in communities".

\section{Critical Thinking}

Teachers teach Civic Education in order to produce a wellinformed citizens. One of $\mathrm{CET}_{4}$ has this to say,

"Through civic education, people are able to argue out and make informed decision especially during democratic campaigns where different candidates approaches one society to sale for their manifestoes. Citizens provide accountability to their leadership because they are empowered by Civic Education".

\section{Skills for Conflict Resolution}

Both administrators and teachers for Civic Education cherished the view that Civic Education provides skills for conflict resolution in communities. $\mathrm{CET}_{5}$ said,

"We teach them a variety of approaches to conflict resolution in Civic Education, hence they are able decide appropriate style depending on the nature of the dispute. Pupil-to-pupil using negotiation, pupil-topupil with prefects as arbitrators, pupil-topupil with a teacher as a mediator are some of the ways in which our learner have employed in resolving conflict at school.

Further, $\mathrm{DHT}_{3}$ added,

"Civic Education helps in conflict resolution as it impart ideals of oneness in the community".

\section{Strategy to Curb Social Challenges}

It was also noted that the teaching of Civic Education serves as a remedy to eradicate or mitigate social challenges in communities. According to $\mathrm{CET}_{6}$,

"Civic Education helps in providing awareness of social challenges which if left unchecked are the source of conflict in the community. Through the establishment of school clubs and associations based on Civic Education, learners are able to sensitise fellow pupils of the dangers of engaging themselves into such illicit activities. Such challenges includes; child defilement, gender based violence, poverty, corruption, property grabbing, and sexual harassment".

Similarly, school administrator also conferred to the views established by teachers that Civic Education in secondary schools helps in curbing social challenges through sensitisation of fellow students. $\mathrm{DHT}_{4}$ explained that,

"Civic Education makes learners realise that the properties of the society belongs to them too, hence need to take care of them. Rioting and vandalism to public infrastructures is discouraged by those taking civic education" 


\section{Appreciation for Cultural Diversity}

The findings revealed the teaching of Civic Education helps in espousing cultural diversity in communities. The views by $\mathrm{CET}_{7}$ and $\mathrm{CET}_{8}$ put together reviewed that,

"Civic Education exist to provide the understanding and appreciation of indigenous culture, while welcoming embracing global culture too. This approach denounces discrimination of other cultures which may lead to racism, xenophobia, genocide and many other anti-social behaviours".

\section{DISCUSSION OF FINDINGS}

\section{Civic Education as a Tool for Conflict Resolution}

The findings that emerged were: Civic Education provides respect for human rights, empower citizens for effective participation in decision making, produce critical thinkers, impart learners will conflict resolution skills, strategy for curbing social challenges and helps in appreciation of cultural diversity. These are key to live in harmony in communities.

\section{Respecting of Human Rights}

The study findings agrees with Halstead and Pike (2006) who explained essential values embedded in Civic Education as: human rights, tolerance, respect for persons or anti-racism which students learn in schools. Through the teaching of Civic Education in secondary schools, students are enlightened of their own fundamental rights and freedoms. Once citizens understand these claims which the state provides, they will pledge to respect others' rights as they exercise theirs. This will reduce issues of conflict in communities as every person understands his or her boundaries with regards to human rights enjoyment. In a pluralist state, a civically minded person is aware of values which govern the community.

The findings reviews that Civic Education helps in promoting human rights, as well as the matter of environmentalism, disarmament and the promotion of a culture of peace. According to Kotite (2012) and Ziile (2021), respect for human rights begins in the family and community and educational institutions can play a critical role in fostering a culture of understanding and respect for human rights. As can be observed, this study and Kotite's explanation coincide with this study as Civic Education is placed at the centre in the enjoyment of fundamental human rights and freedom which is a conduit to sustainable conflict resolution in communities. At the secondary school level in Zambia, leaners are given knowledge on the characteristics of human rights as well as ways of enforcing them. It is in Civic Education where a citizen may be made aware that his or her rights are violated, hence a need to take a step in reporting such infringements to relevant authorities.

\section{Effective Participation in Decision Making}

Various views collected from respondents suggest the benefits found in Civic Education as enhancement of effective participation in decision making. Learners who have studied
Civic Education have unique abilities to participate in the decision making in democratic communities. Vasiljevi (2009) wrote that Civic Education aims at imparting competences that enables citizens to effectively participate in democratic actions of the community. Leaning about democratic actions agrees with the current study findings where Civic Education helps learners know about democratic practices in communities. These democratic ideals include among others; citizen free participation, existence of political parties, political tolerance, and respect for human rights. Crick (2000) relate Civic Education to education where citizens are well trained for effective participation in politics and economy of the community. Democratic governance entails the responsibilities of citizens to choose the mode of government to put in power through a peaceful secret ballot. This confers with Halstead and Pike's (2006) study where Citizenship Education provides political literacy, moral and social responsibility for community involvement. Civic Education provides a rightful approach to conflict resolution which trains citizens to transform from violent to peaceful mind-sets as they commit their time for community participation.

\section{Critical Thinking}

The findings of the current study confirm with Ministry of Education (1996) document which outlines the provision of education which helps learners to develop desirable intellectual skills and qualities such as reflective reasoning and logical thinking. Civic Education empower citizens with skills for analysing public policy development and actions taken by policy implementers in executing such strategies. Citizens provides accountability to political leadership so that they are transparent in the use of public resources. Because of Civic Education, citizens do not take a freelance status in governance matters, they are able to make informed decisions during democratic campaigns for those seeking public office. Such skills are limited in those lacking Civic Education knowledge offered formally in schools. Such involvement clear out uncertainties that may arise when citizens are not involve in governance of their community.

\section{Skills for Conflict Resolution}

The findings confirmed that the teaching and learning of Civic Education in secondary schools instil conflict resolution skills in children. These skills are identified in leaners whilst still in school through their engagement in disputes resolution that arise among them. They are able to employ conflict resolution strategies they learn in class to settle any misunderstanding within themselves or with external persons like teachers or any other member in the school community before school management is involved. Further, they are privileged to know how conflict develop at different levels, in turn enables them identify a suitable conflict resolution strategy. For instance, conflict involving individuals, groups or communities; avoidance, compromise, flow pattern, accommodation, threats and fight are identified as suitable strategies to resolve the dispute (Victor, 2012; Thakore, 2013; Rahim, 1986; Owusu, 
2007; \& Ryan, 2015). However, knowing the best strategy to resolve conflict may not be a sustainable tool for conflict resolution in communities, hence the effective use of Civic Education has a potential to make citizens cherish peaceful existence in communities. It is not ideal to know conflict resolution strategies and wait for conflict to emerge because such skills may have their own limitations especially multicultural communities like Zambia. Therefore, the present study re-echo the use of Civic Education which transforms the mind-set of citizens to cherish culture of peace and denounce conflict at all levels in the communities.

\section{Strategy to Curb Social Challenges}

It was established that Civic Education helps learners with information on social challenges which communities encounter. The most outspoken among others includes; property grabbing, child abuse, drug abuse, defilement, corruption, rape, gender based violence and poverty. These challenges are potential sources of both structural and violent conflict the communities. Similar views are recorded in Gregg (2012) who argued that many countries facing structural violence have a potential of transforming it into violence conflict. With the knowledge and skills vested in citizens, they are able to engage the community to refrain from such ancient practices. Through such engagement, the public will be at peace as all members of the community will respect others even when their cultural practices seem primitive. For instance, Smith-Höhn (2009) argued that gender matters like gender roles, equality and equity are sources of conflict in most communities. Some of these beliefs causes structural conflict in communities which negatively affect the ability of women to participate in political and economic programs.

Another emphasis which was placed in the teaching of Civic Education was sensitisation on the dangers of property grabbing in the society especially if the husband dies. Relatives to the deceased organises themselves in order to seize essential properties of the deceased. This causes a lot of conflict in the community between relatives of the deceased and surviving spouse. Therefore, Civic Education at senior secondary school prepare learners to be advisors in the community where such evils are common.

\section{Appreciation for Cultural Diversity}

It was also demonstrated through this study that Civic Education in secondary schools enables citizens to be aware of cultural diversity of their community. Similarly, Nabavi (2010) emphasised the importance of Civic Education in understanding of one's culture. Civic Education in schools enables one to know his or her cultural rights and identity. The understanding of cultural rights and identity promote coreexistence as citizens cherish their own cultures in respect of others' in a heterogeneous communities. Civic Education provides knowledge and skills on how multicultural communities like Zambia should live in peace. Learners will understand their cultural practices and be able to appreciate those of other ethnic groups in the same community. Through such understanding, the cultural stereotype which can result to conflict between deferent groups of people in the community will be denounced. Citizens will cherish the spirit of oneness through embodying of such traditional practices. Therefore, this study suggested the use of Civic Education in secondary schools in Zambia to serve in providing clarity such cultural practices in relation core-existence in communities.

\section{CONCLUSION}

This study was set to examine the teaching of Civic Education and how it serves as a tool for conflict resolution in the community. The study demonstrated that Civic Education provide awareness to citizens on the fundamental rights and freedoms; empower citizens for effective participation in decision making, produce critical thinkers, impart learners will conflict resolution skills, strategy for curbing social challenges and helps in appreciation of cultural diversity. Such knowledge and skills provide in the teaching of Civic Education have a potential to transform a violent community to a peaceful community. Civic knowledge, skills and values obtained by learners Civic Education are key to conflict resolution in the community.

\section{RECOMMENDATIONS}

The following were the major recommendations from the study:

1. Continuous Professional Development (CPD) activities such as Lesson Study Circle, Cluster Meetings and Professional Subject Associations Workshops must be strengthen in schools to revive Civic Education teachers with new knowledge and skills in teaching Civic Education for conflict resolution in the community.

2. The government should come up with a clear policy that will empower young people through the teaching of Civic Education to organise school associations aimed at promoting peaceful core-existence in multicultural communities as outline in the 2013 Zambia education curriculum framework.

\section{REFERENCES}

[1] Agbu, O. (2006). Theories in Conflict Management. Lagos: National Open University of Nigeria.

[2] Bobbins, S. P. (1974). Managing organizational conflict: A nontraditional approach. Englewood Cliff: Prentice Hall.

[3] Branson, M. S. (1998). The Role of Civic Education: A Forthcoming Education Policy Task Force Position Paper from the Communitarian Network. Washington DC: Center for Civic Education.

[4] Creswell, J. W. (2003). Research design: Qualitative and quantitative approaches (3rd Ed.). London: Sage Publication.

[5] Crick, B. (2000). Essays on Citizenship. London: Continuum.

[6] Debbie. V. C. and Stacey, A. B. (2016). "Encouraging Civic Knowledge and Engagement: Exploring Current Events through a Psychological Lens". Journal of the Scholarship of Teaching and Learning, Vol. 16(2).

[7] Ebimaro, S. (2008). Third Party Intervention in Conflict Resolution. Lagos: National Open University of Nigeria.

[8] Galtung, J. (1969). 'Violence, Peace \& Peace Research', Journal of Peace Research. 6(3), pp. 167-191. 
[9] Galtung, J. (1990). 'Cultural Violence', Journal of Peace Research, 27(3), pp. 291-305.

[10] Gonclaves, M. (2008). Conflict Resolution: Concepts and Practice. New York: ASME.

[11] Halstead J. M and Pike, M. A. (2006). Citizenship and Moral Education Values in Action. London: Routledge.

[12] Kamp, M. (2011). Facilitation Skills and Methods of Adult Education: A Guide for Civic Education at Grass-root Level. Kampala: Konrad-Adenauer-Stiftung.

[13] Kaumba, C. (2015). An Examination of Student's Perceptions of Public Participation in National Governance: A Case of University of Zambia. A Dissertation submitted in partial fulfilment of the requirements for a Master of Education in Civic Education at the University of Zambia. Lusaka: Unpublished.

[14] Kotite, P. (2012). Education for conflict prevention and peacebuilding: Meeting the global challenges of the 21st century. Paris: International Institute for Educational Planning.

[15] Makano, R.F. and Mukanda, V.M. (2019). "Participatory Action Research and Prospects for Electoral Conflict Prevention in Zambia”. Journal of International and Global Studies. 10(2).

[16] McCowan, T. (2009). Rethinking Citizenship Education: A Curriculum for Participatory Democracy. London: Continuum International Publishing Group.

[17] MOESVTEE (2013). Zambia Education Curriculum Framework 2013. Lusaka: CDC.

[18] Muleya, G. (2015). The teaching of Civic Education in Zambia: An Examination of trends in the teaching of Civic Education in Schools. PhD dissertation: University of South Africa.

[19] Muleya, G. (2019). "Re-examining the Concept of Civic Education". Journal of Lexicography and Terminology. 2(2).
[20] Olaniyi, R. (2009). History of Conflicts in Nigeria. Lagos: National Open University of Nigeria.

[21] Owusu-Mensah, M. (2007). Conflict in the Primary School and its Effects on Teaching and Learning: A Case Study of Ejisu-Juaben District. Master's Thesis Department of General Art Studies, Kwame Nkrumah University of Science and Technology, Ghana.

[22] Peterson, A. (2011). Civic Republicanism and Civic Education. London: CPI Antony Rowe.

[23] Piñgul, F. S. (2015). Measuring the Impact of a Supplemental Civic Education Program on Students' Civic Attitude and Efficacy Beliefs. Journal of Education and Training Studies, 3(2). Pasig City: Redfame Publishing

[24] Rahim, A.M. (1986). Managing Conflict in Organizations. New York: Pracger Publishers.

[25] Reyes, J. (2015). Direct And Indirect Forms Of Violence \& Education: The need for a relevant response for out-of-school boys and girls. Geneva: UNESCO.

[26] Robbins, S. (2001). Organizational Behvaiour. (9th Ed). New York: Prentice Hall Inc.

[27] Salvage J, Rowson M, Melf K and Sandøy I. (2012). Structural violence and the underlying causes of violent conflict $\left(2^{\text {nd }} e d\right.$.). London: Routledge.

[28] Stiles, C. E. (2011). Countering Structural Violence: Cultivating an Experience of Positive Peace. A thesis submitted in partial fulfilment of the requirements for the degree of Master of Arts, Portland State University: unpublished.

[29] Thakore, D. (2013). 'Conflict and Conflict Management', Journal of Business and Management. 8(6), pp. 7-16.

[30] Vasiljevic, B. (2009). Civic Education as a Potential for Developing Civil Society and Democracy. Troms $\varnothing$ : University of Tromsø. 